\title{
The effectiveness of depression management for improving HIV care outcomes in Malawi: protocol for a quasi-experimental study
}

Michael Udedi ${ }^{1,3^{*}}$ D, Melissa A. Stockton², Kazione Kulisewa ${ }^{3}$, Mina C. Hosseinipour ${ }^{4,5}$, Bradley N. Gaynes ${ }^{5}$, Steven M. Mphonda ${ }^{4}$ and Brian W. Pence ${ }^{2}$

\begin{abstract}
Background: Depression, prevalent among people living with HIV (PLWH) in Malawi, is associated with negative HIV patient outcomes and likely affects HIV medical management. Despite the high prevalence of depression, its management has not been integrated into HIV care in Malawi or most low-income countries.

Methods: This study employs a pre-post design in two HIV clinics in Lilongwe, Malawi, to evaluate the effect of integrating depression management into routine HIV care on both mental health and HIV outcomes. Using a multiple baseline design, this study is examining mental health and HIV outcome data of adult ( $\geq 18$ years) patients newly initiating ART who also have depression, comparing those entering care before and after the integration of depression screening and treatment into HIV care. The study is also collecting cost information to estimate the cost-effectiveness of the program in improving rates of depression remission and HIV treatment engagement and success.

Discussion: We anticipate that the study will generate evidence on the effect of depression management on HIV outcomes and the feasibility of integrating depression management into existing HIV care clinics. The results of the study will inform practice and policy decisions on integration of depression management in HIV care clinics in Malawi and related settings, and will help design a next-step strategy to scale-up integration to a larger scale.
\end{abstract}

Trial registration: ClinicalTrials.gov ID [NCT03555669]. Retrospectively registered on 13 June 2018.

Keywords: HIV/AIDS, Mental health, Depression, Sub-Saharan Africa, Malawi, Integration, Task-shifting, Program evaluation, Implementation science, Retention

\section{Background}

The Joint United Nations Programme on HIV/AIDS (UNAIDS) "90-90-90" goals provide a compelling roadmap toward achieving the end of the HIV epidemic. The UNAIDS plan, which has been embraced by the international public health community and much of subSaharan Africa, calls for $90 \%$ of those HIV-infected to be aware of their status, $90 \%$ of those aware of their status to be on sustained antiretroviral therapy (ART), and 90\%

\footnotetext{
*Correspondence: mphatsoudedi@yahoo.co.uk

${ }^{1}$ NCDs and Mental Health Unit, Ministry of Health, P. O. Box 30377, Capital City, Lilongwe 3, Malawi

${ }^{3}$ Department of Mental Health, University of Malawi, College of Medicine, P/ Bag 360, Chichiri, Blantyre 3, Malawi

Full list of author information is available at the end of the article
}

of those on ART to be virally suppressed [1]. Achievement of these goals is expected to dramatically reduce or end the HIV epidemic $[1,2]$. In parts of sub-Saharan Africa (SSA), early retention in HIV care is a major obstacle to achieving the UNAIDS 90-90-90 goals. While adherence and viral suppression among those remaining in care is high [3], initiation of and retention in ART treatment (the "second 90") has been challenging. The first year of ART treatment is a particularly vulnerable period: nearly a quarter of people initiating ART are lost to care within the first 12 months, with the majority of loss to care after the first visit or within the first few months of care [4-6].

(c) The Author(s). 2019 Open Access This article is distributed under the terms of the Creative Commons Attribution 4.0 International License (http://creativecommons.org/licenses/by/4.0/), which permits unrestricted use, distribution, and 
Comorbid depression renders people living with HIV vulnerable. Comorbid depression affects patients receiving ART [7] as it is a barrier to ART retention [8, 9], associated with reduced ART adherence and viral suppression [7, 10-12].

Malawi, with a population of 17.5 million, has an adult HIV prevalence of 10\% [13] and barriers reflecting challenges experienced elsewhere in sub-Saharan Africa. The Malawi Ministry of Health $(\mathrm{MoH})$ has embraced the UNAIDS plans and has been a leader and innovator in expansion of antiretroviral therapy (ART) treatment programs. Yet retention in HIV care has been challenging, with only $76 \%$ of adults initiating ART being retained in care at 12 months, and only $65 \%$ being both retained in care and virally suppressed [14]. Depression is prevalent among HIV-infected adults in Malawi $[15,16]$ and is associated with decreased retention in care and viral suppression [7$12,17-20]$. However, Malawi has few psychiatrists and psychiatric wards to provide care [21]. The $\mathrm{MoH}$ is working to build capacity through task-sharing approaches, including training primary care providers and outreach workers in mental health screening and counselling [22-24].

Depression is a prime target for strategies to improved HIV outcomes in Malawi. Depression treatment has been linked to improved ART adherence in a metaanalysis comparing those receiving vs. not receiving depression treatment [25], a conclusion consistent with many observational studies $[20,26,27]$, although evidence from intervention studies is mixed [28-33]. Preliminary evidence suggests that depression care may improve HIV outcomes in Africa [34-38]. In a pilot study of the integration of antidepressant management into HIV clinical care in Cameroon, in which patients with HIV and depression received treatment of amitriptyline, $87 \%$ of patients achieved full remission of their depression within 3 months [37]. Furthermore ARV adherence, viral suppression, and self-reported health also improved. Although the Cameroon study was a singlearm pilot with no comparison group, it suggests that appropriate depression care for people initiating ART may be important to achieve the 90-90-90 goals. However, more robust evidence of the impact of depression treatment on HIV care retention and treatment outcomes will be critical to help guide the allocation of resources to optimize HIV treatment outcomes.

The purpose of this paper is to present the protocol for a quasi-experimental study designed to estimate the effect of the integration of depression treatment into routine HIV primary care on both mental health and HIV-related outcomes in Malawi.

\section{Methods/design}

\section{Purpose}

Our evaluation study has two objectives. The primary objective of this evaluation is to assess the impact of a pragmatic, scalable mental health treatment program on HIV care outcomes including retention in care and viral suppression. The secondary objective of this study is to evaluate the impact of the mental health treatment program on mental health outcomes, including depression remission and depression response.

Specifically, our study is designed to evaluate the following hypotheses:

\section{Primary}

H1 Compared to the period prior to the depression treatment program, adults with HIV and depression during the implementation of the treatment program will be more likely to be retained in HIV care and virally suppressed 6 months after ART initiation (primary outcome).

\section{Secondary}

H2 Compared to the period prior to the depression treatment program, adults with HIV and depression during the implementation of the treatment program will be more likely to be virally suppressed 6 months after ART initiation.

H3 Compared to the period prior to the depression treatment program, adults with HIV and depression during the implementation of the treatment program will be more likely to be retained in HIV care 6 months after ART initiation.

H4 Compared to the period prior to the depression treatment program, adults with HIV and depression during the implementation of the treatment program will have higher HIV care appointment adherence (proportion of scheduled visits that were attended) over the first 6 months on ART.

H5 Compared to the period prior to the depression treatment program, adults with HIV and depression during the implementation of the treatment program will be more likely to have achieved depression remission 6 months after ART initiation.

\section{Study design}

The study employs a multiple baseline evaluation design in two clinics to evaluate the impact of the integrated depression treatment program on HIV outcomes (Fig. 1) . The reasons for the choice of the study design has been described published elsewhere [39].

Study activities will last 27 months. This period includes abstracting depression screening data on patients starting ART over a 20-month period and abstracting additional treatment and outcome data for an additional 7 months to identify follow-up viral load, appointment attendance, and depressive symptom outcomes. An additional 3 months is anticipated to complete data abstraction, analyses and dissemination activities. 


\section{Area 18 Screening Treatment Area 25 \begin{tabular}{l|l} 
Screening & Treatment \\
\hline
\end{tabular} $\begin{array}{llll}0 & 5 & 10 & 15\end{array}$ Months}

Fig. 1 Program implementation Phases

\section{Measures}

We are abstracting data on HIV and mental health outcomes for patients newly initiating ART who screen positive for depression (Table 1).

Depressive severity is being measured using the Chichewa version (vernacular language for Malawi) of the Patient Health Questionnaire (PHQ)-9. The score of 5-9 on the PHQ-9 is considered mild depression while that of 10 and above is moderate to severe depression [40]. Providers screen all patients for depression at the time of ART initiation by administering the PHQ-9 rather than self administration because of the low literacy levels among the patients. Patients who score $\geq 5$ at ART initiation are re-assessed with the PHQ-9 by the HIV provider at each subsequent ART visit. This information is captured on a form called the Mental Health Mastercard that is kept with the patient's HIV file.

Depression Remission will be defined as a PHQ-9 score $<5$ at 6 months.

Retention in HIV care will be defined as being "on time" to all scheduled ART return visits in the first 6 months on treatment. "On time" will be defined as no more than 30 days late; a secondary, tighter definition will define "on time" as no more than 14 days late At ART initiation and each subsequent ART appointment, providers give patients a follow-up appointment date and a sufficient supply of ART. This information is recorded in the patient's chart, called an HIV Mastercard, and in the Electronic Medical Record (EMR). However, generally for the first 6 months of care, new ART patients receive a 30-day supply of ART and a return appointment date in 30 days. Most often, patients need to attend monthly ART refill appointments for their first 6 months of care in order to maintain ART supply through 6 months.
Consistent ART supply will be defined as never going more than 5 days without ART in the first 6 months, calculated from the days' supply of ART dispensed at each appointment in the first 6 months and the time between appointments.

Viral Suppression will be defined as a viral load $<1000$ copies/mL at 6 months. A viral load threshold of 1000 copies/ml was chosen as this is the threshold used in the resource-limited Malawian health care system to guide decisions about treatment failure and second-line alternatives. Viral load testing is performed at Bwaila Hospital in Lilongwe using Abbott m2000 RealTime HIV-1 assay instruments with a lower limit of detection of 40 copies $/ \mathrm{mL}$. The results of the viral load test are recorded in the EMR.

\section{Intervention program}

We integrated depression screening and treatment into ART care into two clinics in Lilongwe, Malawi using a multiple baseline design in two phases: a screening phase and a treatment phase.

During the screening phase, HIV care providers screened patients for depression and monitored their depressive symptoms using the Patient Health Questionnaire-9 (PHQ9). HIV care providers managed patients identified with depression according to existing care pathways, which included: 1) counselling by the HIV care provider; 2) referral to an on-site or off-site psychiatric nurse or other mental health specialist; or 3) in acute cases, transport to the outpatient psychiatric unit at the nearby district hospital.

At the launch of the treatment phase, HIV care providers were trained in algorithm-guided antidepressant management [38]; additionally, clinic-based lay health workers completed training in the Friendship Bench problemsolving therapy counselling protocol [38]. During this

Table 1 Measures

\begin{tabular}{lll}
\hline & Measure & Source \\
\hline Viral Load & viral load copies/mL Point & Mastercard or EMR \\
Appointment Attendance & Appointment Dates & Mastercard or EMR \\
Depressive severity & PHQ-9 Scores & Mastercard \\
\hline
\end{tabular}

EMR Electronic Medical Record 
phase, providers are continuing to screen patients for depression. The providers manage cases of depression identified during the treatment phase with either antidepressants or problem-solving therapy, and providers monitor their depression treatment response at follow-up visits.

\section{Algorithm-based care for depression (ABCD)}

We adapted an $A B C D$ antidepressant prescription model. $\mathrm{ABCD}$ is a resource-efficient, task-sharing model for delivering high quality, effective, safe antidepressant management in non-psychiatric settings. $\mathrm{ABCD}$ equips nonspecialists (e.g., primary care clinicians or HIV clinicians) to safely and effectively prescribe and monitor antidepressants. The model trains staff to know what to measure (e.g., depressive severity, side effects, adherence), how and when to measure it, how to interpret the results, and what resulting course of action to pursue (e.g., maintain dose, increase dose, address side effects, switch medication). Key features include (1) treatment decisions guided by regularly measured metrics of depressive severity, side effects, and adherence; (2) an algorithm summarizing bestpractices care based on metrics; (3) a treatment goal of remission (full resolution of symptoms); (4) low starting dose followed by dose adjustments until remission, as long as the medication remains tolerable; (5) ensuring an adequate trial (six to eight weeks at moderate to high dose); and (6) regular structured supervision for continuous quality improvement.

In our program, a patient initiates an antidepressant when identified with moderate to severe depressive severity (PHQ-9 score $\geq 10$ ) combined with clinical confirmation of the presence of depression (Fig. 2). Every four weeks at the monthly ART appointment, considered critical decision points (CDPs), the patient reports depressive severity and side effects using standardized measures. These metrics guide a recommendation to increase, maintain, or decrease the antidepressant dose or to change treatments. If the patient is tolerating the medication but depressive symptoms have not remitted, a dose increase is recommended. If side effects are not tolerable, the recommendation is to address them or switch treatment. At CDP3 (i.e., after 12 weeks), the patient has either achieved remission (and enters a maintenance phase) or has demonstrated treatment resistance to the current medication (and receives a new treatment plan).

$\mathrm{ABCD}$ has proven to be effective in primary care [41, 42] and in HIV care [30, 43] in high-income countries, and more recently has demonstrated safety, feasibility, and acceptability when adapted for HIV care and delivered by a general practice medical providers in Cameroon, Tanzania and Uganda [34, 44, 45].

\section{.Friendship bench problem-solving therapy (PST)}

We adapted a PST intervention developed for use in Zimbabwe called the Friendship Bench [38]. PST is a psychological treatment that focuses on teaching patients how to identify triggers and effectively manage stressful life events by learning or reactivating problem solving skills [46]. PST evolved from social problem solving theory, framing three sequential phases for addressing problems including (1) discovery (identifying solution), (2) performance (implementing solution), and (3) verification (assessing outcome) [47]. The goal-oriented approach is a cognitive-behavioral intervention focused on improving an individual's coping abilities through psychoeducation, interactive problem-solving exercises, and developing action plans aimed at reducing psychological distress. PST is easy to learn, has been integrated successfully into primary care settings [48], and is an effective strategy for depression management [49-51].

The original Friendship Bench consisted of taskshifting PST to lay health workers in Zimbabwe; requiring minimal training with structured supervision. The Friendship Bench PST intervention resulted in clinically meaningful improvement in mental health outcomes [38] and was highly acceptable among patients with perceived positive benefits [52, 53]. Other studies from SSA have confirmed the feasibility and effectiveness of PST for management of common mental disorders, including depression $[54,55]$.

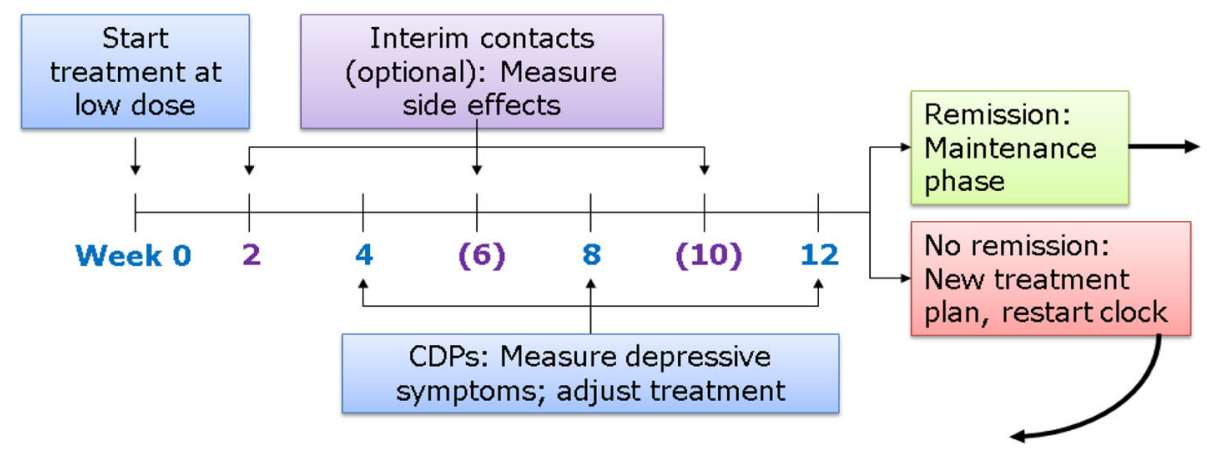

Fig. 2 Algorithm-based care for depression (ABCD) Timeline 
In our program, the developers of the 'Friendship Bench' conducted a training for trainers who then went on to train a team of community health workers stationed at each clinic to deliver PST. The program built structures at both clinics for holding Friendship Bench PST sessions. Additionally, we staffed one Friendship Bench counsellor at each clinic throughout the duration of the program.

\section{Combined intervention}

Our intervention combined ABCD and PST into a stepped-care intervention with clinical response appropriate to the level of depressive severity (Fig. 3). Patients scoring $0-4$ on the PHQ-9, indicating no depression, receive no intervention. Patients scoring 5-9 on the PHQ9, indicating mild depressive symptoms, receive Friendship Bench PST. Patients scoring $\geq 10$ on the PHQ-9, indicating moderate to severe depressive symptoms, are offered $\mathrm{ABCD}$ as the first treatment option, since literature indicates that medications and counselling are equally effective for this group and medication management can be offered more efficiently as first-line within existing clinical care. For this group, Friendship Bench PST is an alternative or augmentation option for those who do not tolerate or do not respond to antidepressant treatment. In all cases, ART providers continue to monitor patients' depressive severity at follow-up visits with the option of modifying their treatment plan if their symptoms worsen or do not improve after three months of an adequate treatment course.

\section{Setting}

We are conducting the evaluation study at two publicsector primary care HIV clinics in Lilongwe, Malawi: Area
18 and Area 25 health clinics. These clinics are managed by Lilongwe District Health Office. More detailed description of the study setting has been published elsewhere.

\section{Population and sample size}

We are abstracting screening data for all consenting adult ( $\geq 18$ years old) patients newly initiating ART and screened for depression at the time of ART initiation at the study sites during the study period. Additional depression treatment and outcome data are being abstracted for all patients who screen positive for mild, moderate, or severe depressive symptoms (PHQ-9 total score $\geq 5)[56,57]$.

We focused on two populations of interest. For the primary population of interest, all patients with depressive symptoms (PHQ-9 score $\geq 5$ ), the original sample size was determined to provide $80 \%$ power to detect an 11 percentage point pre-post difference in the primary outcome. For the secondary (smaller) population of interest, all patients with moderate to severe depression (PHQ-9 score $\geq 10$ ), the original sample size would provide the same power to detect an 18 percentage point pre-post difference. To achieve this power, we would require 645 patients with any depressive symptoms and 225 patients with moderate to severe depressive symptoms.

Based upon the historical rate of new ART patients (122 per month between the two clinics) and the expected prevalence of any depressive symptoms (35\%) and moderate to severe depressive symptoms (12\%) based on prior literature [58] [7], we originally planned for a 15-month data collection period to accrue the targeted sample. During the course of data collection, the rate of new ART patients was higher than expected but the prevalence of depressive symptoms was lower than

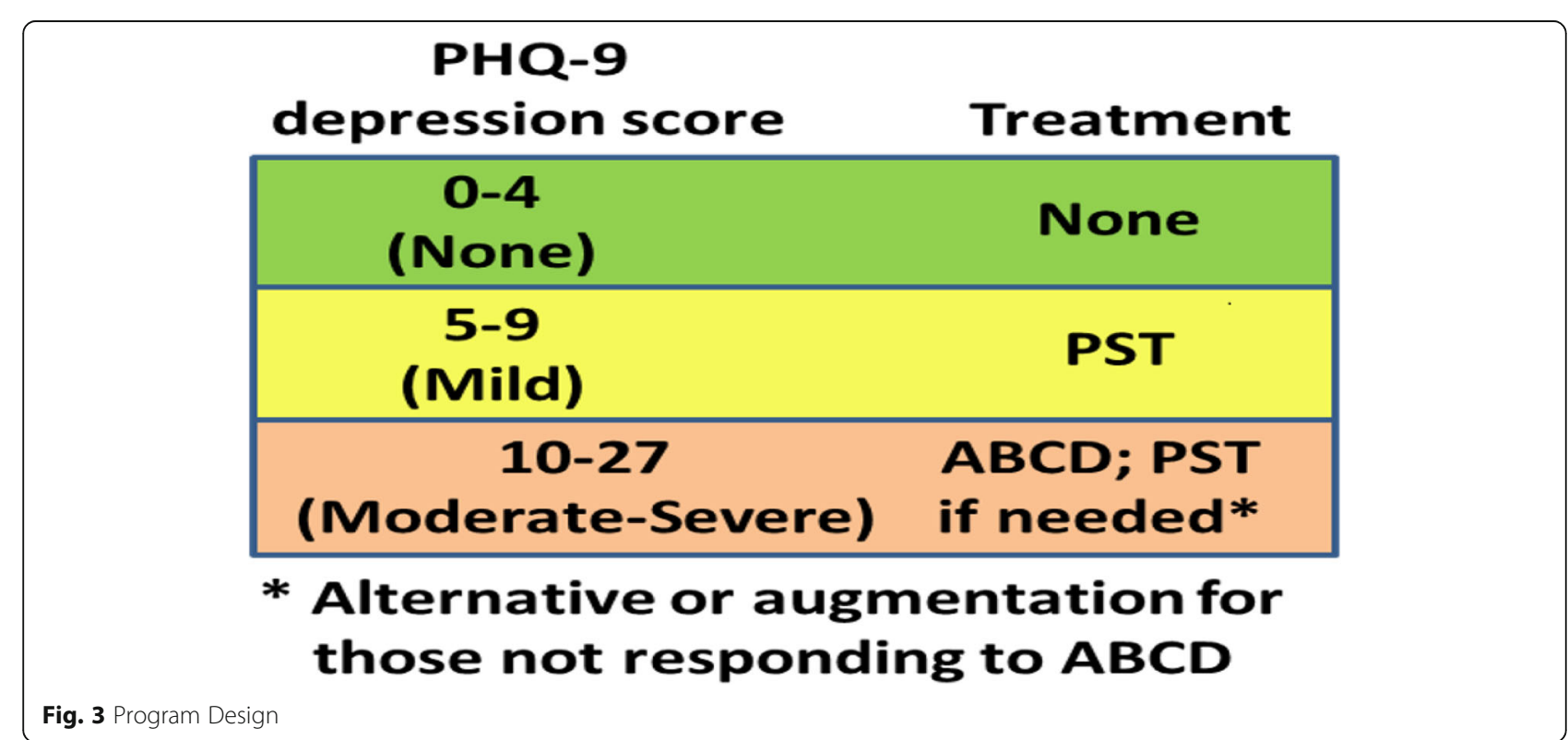


expected. After extending the recruitment period for an additional 5 months, the accrual of new ART patients concluded with a final sample of 2084 individuals. The prevalence of mild to severe depression was $24.1 \%$ ( $n=$ $502)$ and the prevalence of moderate to severe depression was $6.3 \%(n=131)$. This sample has $80 \%$ power to detect a slightly larger difference in the primary outcome of 12 percentage points (e.g. $60 \%$ vs. $72 \%$ ) or a risk ratio of 1.2 for those with mild to severe depression. For those with moderate to severe depression, the sample has $80 \%$ power to detect an improvement in the primary outcome of 22 percentage points (e.g. 60\% vs. $82 \%$ ) or a risk ratio of 1.4 .

\section{Data abstraction and management}

Data on viral loads, HIV appointment attendance, and depressive symptoms is abstracted from electronic and paper medical records and the depression treatment registry at the sites. ART appointment data including the date of the appointment, the expected return date, and medication prescribed is recorded in the EMR, on a paper patient file (called an HIV Mastercard), or both. The results of the viral load tests are recorded in the EMR. Data on patients' depressive symptoms and depression treatment are only recorded on paper in an additional patient filed attached to the ART mastercard (called a mental health mastercard). The community health workers responsible for administering the Friendship Bench problem-solving therapy also maintain paper records (called a Counselling Mastercard) that capture engagement with the PST sessions. Cost information was collected using a time-audit approach to estimate costs of delivering the program, including the opportunity cost of training participation and the time providers and supervisors spend to deliver and supervise the program. Time-audit data was captured through a combination of direct observation of medical provider and counsellor encounters supplemented with selfreporting by counsellors.

\section{Data analysis}

The primary program evaluation question is whether the depression treatment program results in improved HIV and mental health outcomes for patients with HIV and depression relative to the standard of care prior to program implementation. The main analysis will follow an "intent-to-treat" approach, classifying patients according to screening vs. treatment phase (unexposed vs. exposed to the program) without regard to actual treatment received. In our main analysis, we will define our primary outcome, retention in HIV care with viral suppression 6 months after starting ART, as never being more than 30 days late to any scheduled return visit in the first 6 months on ART and having a viral load $<1000$ copies/
$\mathrm{mL}$ at 6 months; patients not retained or not suppressed will be coded as a failure. (Table 2) This composite outcome was chosen as the primary outcome because it is the definition of ART clinical success in the Malawian ART treatment system; those not retained and those retained but not suppressed are both clinical failures. This main analysis will estimate the probability of retention and viral suppression 6 months after starting ART using a generalized linear model with binomial error distribution, adjusting for calendar time and potential confounders that are imbalanced between arms at baseline, potentially including age, sex, clinic, PHQ-9 score, and presence of suicidal ideation. We will model these associations using separate generalized linear models among two samples: (a) those with mild, moderate, or severe depression (PHQ-9 $\geq 5$ ) and (b) those with moderate to severe depression (PHQ-9 $\geq 10$ ).

In secondary analyses, we will consider ART care retention through 6 months (binary), number of ART appointments attended in the first 6 months (count), maintaining consistent ART supply through 6 months (binary), and viral suppression at 6 months among those retained (binary). Further, secondary analyses will take an "as treated" approach, comparing patients who receive treatment in the treatment phase to all patients during the screening phase; and an "as adequately treated" approach, comparing patients who receive adequate treatment ( $\geq 3$ consecutive months of protocolconcordant antidepressant prescriptions or $\geq 4$ counseling sessions) during the treatment phase to all patients during the screening phase. Data are not available on antidepressant adherence. (Table 3).

\section{Timeline}

The screening phase began at Clinic A in April 2017 and Clinic B in May 2017. The treatment phase was integrated into Clinic A after 7 months, in November 2017, and into Clinic B after 11 months, in April 2018. Identification of new patients concluded at both clinics in November 2018. Follow-up data abstraction is expected to continue through June 2019.

\section{Discussion}

This novel pilot program is Malawi's first depression treatment program for people living with HIV and one of the few in the sub-Saharan Africa region to use a task-shifting model to provide both problem-solving therapy and antidepressant depression treatment [3438]. This study will be the first to evaluate the impact of such a program on both mental health and HIV outcomes and to investigate the potential benefits of this task-shifting depression care model. Findings from this study will directly inform the Malawi Ministry of Health's ongoing national strategic plans on mental health. 
Table 2 Outcome Variables

\begin{tabular}{|c|c|c|}
\hline & Definition & Type \\
\hline \multicolumn{3}{|l|}{ Primary Outcome } \\
\hline $\begin{array}{l}\text { Retention with Viral } \\
\text { Suppression }\end{array}$ & $\begin{array}{l}\text { both attending all ART appointments "on } \\
\text { time" through } 6 \text { months and having a viral } \\
\text { load }<1000 \text { copies/mL at } 6 \text { months }\end{array}$ & Binary \\
\hline \multicolumn{3}{|l|}{ Secondary Outcomes } \\
\hline Viral Suppression & viral load $<1000$ copies $/ \mathrm{mL}$ at 6 months & Binary \\
\hline \multirow[t]{2}{*}{ Retention } & $\begin{array}{l}\text { attending all ART appointments "on time" } \\
\text { through } 6 \text { months }\end{array}$ & Binary \\
\hline & $\begin{array}{l}\text { number of ART appointments attended } \\
\text { through } 6 \text { months }\end{array}$ & Count \\
\hline $\begin{array}{l}\text { Consistent ART } \\
\text { supply }\end{array}$ & $\begin{array}{l}\text { Never going more then } 5 \text { days without } \\
\text { ART, as calculated from pills dispensed and } \\
\text { time between attended appointments }\end{array}$ & Binary \\
\hline $\begin{array}{l}\text { Depression } \\
\text { Remission }\end{array}$ & PHQ-9 Score $<5$ at 6 months & Binary \\
\hline
\end{tabular}

The study design draws both from implementation science and epidemiologic methods, with the ultimate goal of generating evidence-based practices, interventions and policies that can readily (and rapidly) be adopted and integrated into routine care in public sector settings [59-61]. We have conscientiously designed the evaluation to yield high quality, real-world findings on integrating depression management into HIV care that are readily applicable to the implementation of integrated mental health services in non-specialist settings.

The program itself focuses on provider training to manage antidepressants and provide evidence-based counselling, and thus cannot be randomized at the individual level. Since patients do not see the same provider from one appointment to the next, in this context the intervention could not be randomized at the provider level either. A cluster-randomized trial was also beyond the resources available for this project. Given these constraints, a multiple baselines design provides stronger causal inference than would be available with a simple pre-post design. Multiple baseline designs have been advocated as one of the designs providing the strongest causal inference apart from the randomized trial [62].

We anticipate that the study will generate evidence on the effect of depression management on HIV outcomes and the feasibility of integrating depression management

Table 3 Analyses

\begin{tabular}{|c|c|}
\hline Analysis & Definition \\
\hline $\begin{array}{l}\text { Primary: "intent- } \\
\text { to-treat" }\end{array}$ & Initiated after program launch \\
\hline "as treated" & Received depression treatment \\
\hline $\begin{array}{l}\text { "as adequately } \\
\text { treated" }\end{array}$ & $\begin{array}{l}\geq 3 \text { consecutive months of protocol-concordant anti- } \\
\text { depressant prescriptions or } \geq 4 \text { counselling sessions }\end{array}$ \\
\hline
\end{tabular}

into existing HIV care clinics. The results of the study will inform practice and policy decisions on integration of depression management in HIV care clinics in Malawi and similar low-income country settings, allowing design of a scale up strategy.

\section{Abbreviations}

ART: Antiretroviral Treatment; EMR: Electronic Medical Record; HIV: Human Immunodeficiency Virus; HTC: HIV Testing and Counseling; IRB: Institutional Review Board; MOH: Ministry of Health; NCDs: Non-communicable Diseases; NHSRC: National Health Science Research Committee; PEPFAR: United States President's Emergency Plan for AIDS Relief; PHQ-2: Patient Health

Questionnaire-2; PHQ-9: Patient Health Questionnaire-9; PST: Problem-solving Therapy; SOAR: Supporting Operational AIDS Research; UNAIDS: Joint United Nations Programme on HIV/AIDS; UNC: University of North Carolina;

USAID: United States Agency for International Development

\section{Acknowledgements}

The team would like to thank the patients who have graciously volunteered their data to be abstracted and used to evaluate this program. Finally, we would like to thank the research assistants who are responsible for consenting patients and abstracting clinical data.

\section{Authors' contributions}

$\mathrm{MU}$ and BP conceived of the study, lead the study design, supported the study implementation and drafted the manuscript. MS participated in the study design, analyzed the data, and drafted and finalized the manuscript. $\mathrm{MH}$ and BG conceived of study, lead study design, supported the study implementation, and assisted in drafting and revising the manuscript. KK participated in study design, supported the study implementation, and assisted in drafting and revising the manuscript. SM participated in study design and coordinated the study implementation, and assisted in drafting and revising the manuscript. All authors read and approved the final manuscript.

\section{Funding}

This study was funded by the generous support of the American people through the United States President's Emergency Plan for AIDS Relief (PEFPAR) and United States Agency for International Development (USAID) under the Cooperative Agreement Project SOAR (Supporting Operational AIDS Research), number AID-OAA-14-00060. The content of this publication is the sole responsibility of the authors and does not necessarily reflect the views or policies of PEPFAR, USAID, and does not imply endorsement by the United States Government.

\section{Availability of data and materials}

The datasets that will be collected and/or analysed over the course of the ongoing study will be available from the corresponding author on reasonable request.

\section{Ethics approval and consent to participate}

The protocol was approved by the National Health Sciences Research Committee of Malawi (NHSRC) and the Biomedical Institutional Review Board (IRB) of the University of North Carolina at Chapel Hill. All research activities adhere to Malawian and US ethical standards for research in human subjects. To ensure protection of patients' identities and confidentiality, the evaluation uses routinely collected, de-identified clinical data to assess this treatment program. None of the patients will be identified in any reports or publications about this evaluation. All data will be analysed collectively so that information from any one patient will remain anonymous. Written informed consent will be obtained from every participant.

\section{Consent for publication}

Not applicable.

\section{Competing interests}

The authors declare that they have no competing interests. 


\section{Author details}

${ }^{1}$ NCDs and Mental Health Unit, Ministry of Health, P. O. Box 30377, Capital City, Lilongwe 3, Malawi. ${ }^{2}$ Department of Epidemiology, University of North Carolina at Chapel Hill, Gillings School of Global Public Health, 135 Dauer Dr, Chapel Hill, NC 27599, USA. ${ }^{3}$ Department of Mental Health, University of Malawi, College of Medicine, P/Bag 360, Chichiri, Blantyre 3, Malawi. ${ }^{4}$ Tidziwe Centre, University of North Carolina Project-Malawi, Private Bag A-104, Lilongwe, Malawi. ${ }^{5}$ Department of Psychiatry, University of North Carolina at Chapel Hill School of Medicine, 333 S Columbia St, Chapel Hill, NC 27516, USA.

Received: 20 April 2019 Accepted: 9 June 2019

Published online: 26 June 2019

\section{References}

1. UNAIDS: 90-90-90: An ambitious treatment target to help end the AIDS epidemic. Available at http://www.unaids.org/sites/default/files/media_ asset/90-90-90_en_0.pdf. Accessed 12/7/2015. In.: UNAIDS; 2014.

2. Cohen MS, Chen YQ, McCauley M, Gamble T, Hosseinipour MC, Kumarasamy N, Hakim JG, Kumwenda J, Grinsztejn B, Pilotto JH, et al. Prevention of HIV-1 infection with early antiretroviral therapy. N Engl J Med. 2011;365(6):493-505.

3. Mills EJ, Nachega JB, Buchan I, Orbinski J, Attaran A, Singh S, Rachlis B, Wu P, Cooper C, Thabane L, et al. Adherence to antiretroviral therapy in sub-Saharan Africa and North America: a meta-analysis. Jama. 2006;296(6):679-90.

4. Fox MP, Rosen S. Retention of Adult Patients on Antiretroviral Therapy in Low- and Middle-Income Countries: Systematic Review and Meta-analysis 2008-2013. J Acquir Immune Defic Syndr. 2015;69(1):98-108.

5. Rasschaert F, Koole O, Zachariah R, Lynen L, Manzi M, Van Damme W. Short and long term retention in antiretroviral care in health facilities in rural Malawi and Zimbabwe. BMC Health Serv Res. 2012;12:444.

6. Massaquoi M, Zachariah R, Manzi M, Pasulani O, Misindi D, Mwagomba B, Bauernfeind A, Harries AD. Patient retention and attrition on antiretroviral treatment at district level in rural Malawi. Trans R Soc Trop Med Hyg. 2009; 103(6):594-600.

7. Nakimuli-Mpungu E, Bass JK, Alexandre P, Mills E, Musisi S, Ram M, Katabira E, Nachega JB. Depression, alcohol use and adherence to antiretroviral therapy in sub-Saharan Africa: a systematic review. AIDS Behav. 2012;16(8):2101-18.

8. Smillie K, Van Borek N, van der Kop ML, Lukhwaro A, Li N, Karanja S, Patel AR, Ojakaa D, Lester RT. Mobile health for early retention in HIV care: a qualitative study in Kenya (WelTel Retain). Afr J AIDS Res. 2014;13(4):331-8.

9. Franke MF, Kaigamba F, Socci AR, Hakizamungu M, Patel A, Bagiruwigize $E$, Niyigena $P$, Walker KD, Epino $H$, Binagwaho $A$, et al. Improved retention associated with community-based accompaniment for antiretroviral therapy delivery in rural Rwanda. Clin Infect Dis. 2013;56(9):1319-26.

10. Pence BW, Miller WC, Gaynes BN, Eron JJ, Jr.: Psychiatric illness and virologic response in patients initiating highly active antiretroviral therapy. J Acquir Immune Defic Syndr 2007, 44(2):159-166.

11. Kidia K, Machando D, Bere T, Macpherson K, Nyamayaro P, Potter L, Makadzange T, Munjoma R, Marufu M, Araya R, et al. 'I was thinking too much': experiences of HIV-positive adults with common mental disorders and poor adherence to antiretroviral therapy in Zimbabwe. Trop Med Int Health. 2015;20(7):903-13.

12. Gonzalez JS, Batchelder AW, Psaros C, Safren SA. Depression and HIV/AIDS treatment nonadherence: a review and meta-analysis. J Acquir Immune Defic Syndr. 2011;58(2):181-7.

13. UNAIDS. UNAIDS DATA 2017. Geneva: Joint United Nations Programme on HIV/AIDS (UNAIDS); 2017.

14. Government of Malawi Ministry of Health. Malawi Integrated HIV Program Report, October-December 2014. Lilongwe, Malawi: Ministry of Health; 2015.

15. Dow A, Dube Q, Pence BW, Van Rie A. Postpartum depression and HIV infection among women in Malawi. J Acquir Immune Defic Syndr. 2014; 65(3):359-65.

16. Kim MH, Mazenga AC, Devandra A, Ahmed S, Kazembe PN, Yu X, Nguyen C, Sharp C. Prevalence of depression and validation of the Beck Depression Inventory-II and the Children's Depression Inventory-Short amongst HIVpositive adolescents in Malawi. J Int AIDS Soc. 2014;17:18965.

17. Rane MS, Hong T, Govere S, Thulare H, Moosa M-Y, Celum C, Drain PK Depression and Anxiety as Risk Factors for Delayed Care-Seeking Behavior in Human Immunodeficiency Virus-Infected Individuals in South Africa. Clin Infect Dis. 2018:ciy309.
18. Turan B, Stringer KL, Onono M, Bukusi EA, Weiser SD, Cohen CR, Turan JM. Linkage to HIV care, postpartum depression, and HIV-related stigma in newly diagnosed pregnant women living with HIV in Kenya: a longitudinal observational study. BMC Pregnancy Childbirth. 2014;14(1):400.

19. Ramirez-Avila L, Regan S, Giddy J, Chetty S, Ross D, Katz JN, Freedberg KA, Walensky RP, Losina E, Bassett IV. Depressive symptoms and their impact on health-seeking behaviors in newly-diagnosed HIV-infected patients in Durban, South Africa. AIDS Behav. 2012;16(8):2226-35.

20. Walkup J, Wei W, Sambamoorthi U, Crystal S. Antidepressant treatment and adherence to combination antiretroviral therapy among patients with AIDS and diagnosed depression. Psychiatry Q. 2008;79(1):43-53.

21. Kauye F, Udedi M, Mafuta C. Pathway to care for psychiatric patients in a developing country: Malawi. Int J Soc Psychiatry. 2015;61(2):121-8.

22. Kauye F, Chiwandira C, Wright J, Common S, Phiri M, Mafuta C, MaliwichiSenganimalunje L, Udedi M. Increasing the capacity of health surveillance assistants in community mental health care in a developing country, Malawi. Malawi Med J. 2011;23(3):85-8.

23. Kauye F, Jenkins R, Rahman A. Training primary health care workers in mental health and its impact on diagnoses of common mental disorders in primary care of a developing country, Malawi: a cluster-randomized controlled trial. Psychol Med. 2014;44(03):657-66.

24. Wright J, Common S, Kauye F, Chiwandira C. Integrating community mental health within primary care in southern Malawi: a pilot educational intervention to enhance the role of health surveillance assistants. Int I Soc Psychiatry. 2014;60(2):155-61.

25. Sin NL, DiMatteo MR. Depression treatment enhances adherence to antiretroviral therapy: a meta-analysis. Ann Behav Med. 2014;47(3):259-69.

26. Tsai AC, Weiser SD, Petersen ML, Ragland K, Kushel MB, Bangsberg DR. A marginal structural model to estimate the causal effect of antidepressant medication treatment on viral suppression among homeless and marginally housed persons with HIV. Arch Gen Psychiatry. 2010;67(12):1282-90.

27. Yun LW, Maravi M, Kobayashi JS, Barton PL, Davidson AJ. Antidepressant Treatment Improves Adherence to Antiretroviral Therapy Among Depressed HIV-Infected Patients. J Acquir Immune Defic Syndr. 2005;38(4):432-8.

28. Tsai AC, Karasic DH, Hammer GP, Charlebois ED, Ragland K, Moss AR, Sorensen JL, Dilley JW, Bangsberg DR. Directly observed antidepressant medication treatment and HIV outcomes among homeless and marginally housed HIV-positive adults: a randomized controlled trial. Am J Public Health. 2013;103(2):308-15.

29. Pyne JM, Fortney JC, Curran GM, Tripathi S, Atkinson JH, Kilbourne AM, Hagedorn HJ, Rimland D, Rodriguez-Barradas MC, Monson T, et al. Effectiveness of collaborative care for depression in human immunodeficiency virus clinics. Arch Intern Med. 2011;171(1):23-31.

30. Pence BW, Gaynes BN, Adams JL, Thielman NM, Heine AD, Mugavero MJ, McGuinness T, Raper JL, Willig JH, Shirey KG, et al. The effect of antidepressant treatment on HIV and depression outcomes: results from a randomized trial. AIDS. 2015;29(15):1975-86.

31. Safren SA, O'Cleirigh C, Tan JY, Raminani SR, Reilly LC, Otto MW, Mayer KH. A randomized controlled trial of cognitive behavioral therapy for adherence and depression (CBT-AD) in HIV-infected individuals. Health Psychol. 2009; 28(1):1-10.

32. Safren $\mathrm{SA}, \mathrm{O}^{\prime}$ Cleirigh $\mathrm{CM}$, Bullis JR, Otto MW, Stein MD, Pollack MH. Cognitive behavioral therapy for adherence and depression (CBT-AD) in HIV-infected injection drug users: a randomized controlled trial. J Consult Clin Psychol. 2012;80(3):404-15.

33. Simoni JM, Wiebe JS, Sauceda JA, Huh D, Sanchez G, Longoria V, Andres Bedoya C, Safren SA. A preliminary RCT of CBT-AD for adherence and depression among HIV-positive Latinos on the U.S.-Mexico border: the Nuevo Dia study. AIDS Behav. 2013;17(8):2816-29.

34. Pence BW, Gaynes BN, Atashili J, O'Donnell JK, Kats D, Whetten K, Njamnshi AK, Mbu T, Kefie C, Asanji S. Feasibility, safety, acceptability, and preliminary efficacy of measurement-based care depression treatment for HIV patients in Bamenda, Cameroon. AIDS Behav. 2014;18(6):1142-51.

35. Chibanda D, Weiss HA, Verhey R, Simms V, Munjoma R, Rusakaniko S, Chingono A, Munetsi E, Bere T, Manda E. Effect of a primary care-based psychological intervention on symptoms of common mental disorders in Zimbabwe: a randomized clinical trial. Jama. 2016;316(24):2618-26.

36. Wagner GJ, Slaughter M, Ghosh-Dastidar B. Depression at Treatment Initiation Predicts HIV Antiretroviral Adherence in Uganda. Journal of the International Association of Providers of AIDS Care (JIAPAC). 2017;16(1):91-7. 
37. Gaynes BN, Pence BW, Atashili J, O'Donnell JK, Njamnshi AK, Tabenyang ME, Arrey CK, Whetten R, Whetten K, Ndumbe P. Changes in HIV outcomes following depression care in a resource-limited setting: results from a pilot study in Bamenda, Cameroon. PLoS One. 2015;10(10):e0140001.

38. Chibanda D, Mesu P, Kajawu L, Cowan F, Araya R, Abas MA. Problem-solving therapy for depression and common mental disorders in Zimbabwe: piloting a task-shifting primary mental health care intervention in a population with a high prevalence of people living with HIV. BMC Public Health. 2011;11:828.

39. Udedi M, Stockton MA, Kulisewa K, Hosseinipour MC, Gaynes BN, Mphonda SM, Mwagomba BM, Mazenga AC, Pence BW. Integrating depression management into HIV primary care in central Malawi: the implementation of a pilot capacity building program. BMC Health Serv Res. 2018;18(1):593.

40. Kroenke K, Spitzer R, Williams J. The PHQ-9: Validity of a brief depression severity measure. Gen Intern Med. 2001;16:606-13. In.

41. Gaynes BN, Rush AJ, Trivedi MH, Wisniewski SR, Balasubramani GK, McGrath PJ, Thase ME, Klinkman M, Nierenberg AA, Yates WR, et al. Primary versus specialty care outcomes for depressed outpatients managed with measurement-based care: results from STAR*D. J Gen Intern Med. 2008; 23(5):551-60.

42. Landis SE, Gaynes BN, Morrissey JP, Vinson N, Ellis AR, Domino ME. Generalist care managers for the treatment of depressed medicaid patients in North Carolina: a pilot study. BMC Fam Pract. 2007:8:7.

43. Adams JL, Gaynes BN, McGuinness T, Modi R, Willig J, Pence BW. Treating depression within the HIV "medical home": a guided algorithm for antidepressant management by HIV clinicians. AIDS Patient Care STDS. 2012; 26(11):647-54.

44. Adams JL, Almond ML, Ringo EJ, Shangali WH, Sikkema KJ. Feasibility of nurse-led antidepressant medication management of depression in an HIV clinic in Tanzania. Int J Psychiatry Med. 2012;43(2):105-17.

45. Wagner GJ, Ngo V, Goutam P, Glick P, Musisi S, Akena D. A Structured Protocol Model of Depression Care versus Clinical Acumen: A Cluster Randomized Trial of the Effects on Depression Screening, Diagnostic Evaluation, and Treatment Uptake in Ugandan HIV Clinics. PLoS One. 2016; 11(5):e0153132.

46. Pierce D. Problem solving therapy - use and effectiveness in general practice. Aust Fam Physician. 2012;41(9):676-9.

47. D'Zurilla TJ, Goldfried MR. Problem solving and behavior modification. J Abnorm Psychol. 1971;78(1):107-26.

48. Hickie IB. An approach to managing depression in general practice. Med J Aust. 2000;173(2):106-10.

49. Bell AC, D'Zurilla TJ. Problem-solving therapy for depression: a meta-analysis. Clin Psychol Rev. 2009;29(4):348-53.

50. Cuijpers $P$, van Straten A, Warmerdam L. Problem solving therapies for depression: a meta-analysis. Eur Psychiatry. 2007;22(1):9-15.

51. Malouff JM, Thorsteinsson EB, Schutte NS. The efficacy of problem solving therapy in reducing mental and physical health problems: a meta-analysis. Clin Psychol Rev. 2007;27(1):46-57.

52. Abas M, Bowers T, Manda E, Cooper S, Machando D, Verhey R, Lamech N, Araya R, Chibanda D. 'Opening up the mind': problem-solving therapy delivered by female lay health workers to improve access to evidence based care for depression and other common mental disorders through the Friendship Bench Project in Zimbabwe. Int J Ment Health Syst. 2016;10:39.

53. Chibanda D, Cowan F, Verhey R, Machando D, Abas M, Lund C. Lay Health Workers' Experience of Delivering a Problem Solving Therapy Intervention for Common Mental Disorders Among People Living with HIV: A Qualitative Study from Zimbabwe. Community Ment Health J. 2017:53(2):143-53.

54. van't Hof E, Stein DJ, Marks I, Tomlinson M, Cuijpers P. The effectiveness of problem solving therapy in deprived South African communities: results from a pilot study. BMC Psychiatry. 2011;11:156.

55. Chibanda D, Shetty AK, Tshimanga M, Woelk G, Stranix-Chibanda L, Rusakaniko S. Group problem-solving therapy for postnatal depression among HIV-positive and HIV-negative mothers in Zimbabwe. J Int Assoc Providers AIDS Care. 2014;13(4):335-41.

56. Lowe B, Kroenke K, Herzog W, Grafe K. Measuring depression outcome with a brief self-report instrument: sensitivity to change of the Patient Health Questionnaire (PHQ-9). J Affect Disord. 2004;81(1):61-6.

57. Lowe B, Unutzer J, Callahan CM, Perkins AJ, Kroenke K. Monitoring depression treatment outcomes with the patient health questionnaire-9. Med Care. 2004;42(12):1194-201.
58. Malava JK, Lancaster KE, Hosseinipour MC, Rosenberg NE, O'Donnell J K, Kauye F, Mbirimtengerenji N, Chaweza T, Tweya H, Phiri S et al: Prevalence and associated factors of probable depression diagnosis and suicidality among patients receiving HIV care in a developing country: Malawi. AIDS patient care and STDs Under review.

59. Government of Malawi Ministry of Health. The National Action Plan for NCDs and Mental Health (2012-2016). Lilongwe, Malawi: Government of Malawi Ministry of Health; 2013.

60. Neta G, Brownson RC, Chambers DA. Opportunities for epidemiologists in implementation science: A primer. Am J Epidemiol. 2017;187(5):899-910.

61. Theobald S, Brandes N, Gyapong M, El-Saharty S, Proctor E, Diaz T, Wanji S, Elloker S, Raven J, Elsey H. Implementation research: new imperatives and opportunities in global health. The Lancet. 2018;392(10160):2214-28.

62. Ferron JM, Moeyaert M, Van den Noortgate W, Beretvas SN. Estimating causal effects from multiple-baseline studies: Implications for design and analysis. Psychol Methods. 2014;19(4):493.

\section{Publisher's Note}

Springer Nature remains neutral with regard to jurisdictional claims in published maps and institutional affiliations.
Ready to submit your research? Choose BMC and benefit from:

- fast, convenient online submission

- thorough peer review by experienced researchers in your field

- rapid publication on acceptance

- support for research data, including large and complex data types

- gold Open Access which fosters wider collaboration and increased citations

- maximum visibility for your research: over $100 \mathrm{M}$ website views per year

At BMC, research is always in progress.

Learn more biomedcentral.com/submissions 